\title{
Emotional interactions and an ethic of care: caring relations in families affected by HIV and AIDS
}

Article

Accepted Version

Evans, R. and Thomas, F. (2009) Emotional interactions and an ethic of care: caring relations in families affected by HIV and AIDS. Emotions, Space and Society, 2 (2). pp. 111-119. ISSN 1755-4586 doi:

https://doi.org/10.1016/j.emospa.2009.08.003 Available at https://centaur.reading.ac.uk/1699/

It is advisable to refer to the publisher's version if you intend to cite from the work. See Guidance on citing.

To link to this article DOI: http://dx.doi.org/10.1016/j.emospa.2009.08.003

Publisher: Elsevier

All outputs in CentAUR are protected by Intellectual Property Rights law, including copyright law. Copyright and IPR is retained by the creators or other copyright holders. Terms and conditions for use of this material are defined in the End User Agreement.

www.reading.ac.uk/centaur 
Central Archive at the University of Reading

Reading's research outputs online 
Article published in Emotions, Space and Society (2009) 2, 111-119.

Emotional interactions and an ethics of care: caring relations in families affected by HIV and AIDS

Ruth Evans ${ }^{1}$ and Felicity Thomas ${ }^{2}$

1. Department of Geography, University of Reading

2. Felicity Thomas, Thomas Corum Research Unit, Institute of Education, University of London

\section{Acknowledgements}

We would like to thank all those who contributed to the research process and in particular, the research participants in Namibia, Tanzania and the UK for sharing their experiences and emotions with us. We are also grateful to the anonymous reviewers, Joyce Davidson and Liz Bondi for their helpful comments on an earlier version of this paper.

(C) Ruth Evans and Felicity Thomas, 12/8/09. Please cite article as: Evans, R. and Thomas, F. (2009) 'Emotional interactions and an ethic of care: caring relations in families affected by HIV and AIDS', Emotions, Space and Society, 2, 111-119. 


\begin{abstract}
In the context of global processes of economic restructuring, the HIV and AIDS epidemic and socio-cultural constructions of care, many women and young people in low-income households have been drawn into caring roles within the family. Drawing on the literature on an ethics of care, emotional geographies and embodiment, this paper examines the emotional dynamics of the caring process in families affected by HIV and AIDS. Based on the perspectives of both 'caregivers' and 'care-receivers' from research undertaken in Namibia, Tanzania and the UK, we examine the everyday practices of care that women and young people are engaged in and explore how emotions are performed and managed in caring relationships. Our research suggests caregivers play a crucial role in providing emotional support and reassurance to people with HIV, which in turn often affects caregivers' emotional and physical wellbeing. Within environments where emotional expression is restricted and HIV is heavily stigmatised, caregivers and care-receivers seek to regulate their emotions in order to protect family members from the emotional impacts of a chronic, life-limiting illness. However, whilst care giving and receiving may lead to close emotional connections and a high level of responsiveness, the intensity of intimate caring relationships, isolation and lack of access to adequate resources can cause tensions and contradictory feelings that may be difficult to manage. These conflicts can severely constrain carers' ability to provide the 'good care' that integrates the key ethical phases in Tronto's (1993) ideal of the caring process.
\end{abstract}

Keywords: ethics of care; HIV and AIDS; emotions and caring relationships; gender and youth; Africa; UK

(C) Ruth Evans and Felicity Thomas, 12/8/09. Please cite article as: Evans, R. and Thomas, F. (2009) 'Emotional interactions and an ethic of care: caring relations in families affected by HIV and AIDS', Emotions, Space and Society, 2, 111-119. 


\section{Introduction and context}

Global processes of restructuring and neoliberal economic policies such as reductions in public health spending and the privatisation of care provision implicitly increase women's and children's unpaid care work within the family (Robson, 2004; Sparr, 1994). Although notions of 'femininity' and gendered constructions of care are culturally defined and historically and geographically contingent, in many societies, caring is often perceived as part of women's and girls' 'natural' roles as nurturers (Tronto, 1993; Graham, 1983; Robson, 2004). Research on informal care within the family has emphasised that caring involves both physical and emotional labour (Finch and Groves, 1983; Milligan, 2003). The emotional labour of care work is likely to be particularly intense in circumstances in which care of chronically ill people is considered the responsibility of informal family carers, located within the private sphere and often hidden from mainstream social and material support networks. This is clearly evident in the context of HIV and AIDS, which remains a highly stigmatised illness in many places in the global North and South, with few opportunities for families to access support outside the immediate household.

This paper examines the emotional dynamics of the caring process based on qualitative research with caregivers and care-receivers in families affected by HIV and AIDS in the UK, Tanzania and Namibia. In Tanzania and Namibia, as in much of Sub-Saharan Africa, overburdened health services, the expense of hospital fees, very limited access to social protection and the stigma associated with HIV and AIDS

(C) Ruth Evans and Felicity Thomas, 12/8/09. Please cite article as: Evans, R. and Thomas, F. (2009) 'Emotional interactions and an ethic of care: caring relations in families affected by HIV and AIDS', Emotions, Space and Society, 2, 111-119. 
mean that for most people, care for family members is located within the home, where adjustments have to be made to accommodate the needs of the chronically ill or disabled person. In this context, the family is endorsed as the dominant provider of care by policies that emphasise home-based care and in which caring activities are regarded as a 'normal' part of familial or kinship responsibilities (Evans and Becker, 2009; Ogden, Esim and Grown, 2006). In both countries, socio-cultural expectations and norms mean that care work is highly gendered, with women and girls considered to be the primary caregivers, although, as our research shows, boys and young men in Tanzania are also involved in care work when female carers are not available. The patrilocal system of marriage in the research site in Namibia meant that women's access to key resources such as land and livestock were very often dependent upon them fulfilling gender-based norms of care work. Therefore, the emotions experienced by carers and those being cared for must be understood within the broader context of existing socio-cultural relations, gender and age inequalities, stigma and poverty within which care work takes place.

In the UK, despite more extensive access to public health care and welfare support, everyday practices of care for people with HIV are still predominantly regarded as a private family matter, strongly gendered and located within the home. The national policy context of cut-backs in social services, the changing perception of HIV as a chronic, rather than a terminal illness due to medical advances in treatment, combined with the fluctuating nature of HIV illness and impairment mean that the support needs of people with HIV may not be considered to meet the thresholds for entitlements to social care provision (Evans and Becker, 2009). For some women who were African 'Emotional interactions and an ethic of care: caring relations in families affected by HIV and AIDS', Emotions, Space and Society, 2, 111-119. 
migrants, these experiences were exacerbated by the emotional stress caused by insecure immigration status and differential entitlements to health care and welfare support, as well as HIV stigma, and these in turn influenced emotional interactions within caring relationships.

While the diversity of the research locations and differences in the backgrounds of the carers (particularly in terms of age) must be acknowledged, this paper discusses common themes that emerged from the perspectives of 'carers' and those being 'cared for' across the three countries that formed the focus of the studies ${ }^{1}$. First, we give a brief overview of theoretical concepts and research on an ethics of care, emotional geographies and embodiment that we draw on throughout the paper and then describe the research methods. Our discussion of the empirical findings explores the closely interconnected and dynamic nature of emotional interactions and support between the 'carer' and the 'cared for'; the ways in which emotions are performed and regulated; the emotional strains and tensions in achieving an integrated process of care due to a lack of access to adequate resources; and care-receivers' feelings about their perceived dependence on caregivers.

\section{An ethics of care and gender}

Since the late 1980s, proponents of the social model of disability have challenged medical models of illness and disability that portray disabled people as passive 'victims' of 'individual medical tragedies' (Shakespeare, 1993, 255; Oliver, 1990; Morris, 1991). They have also highlighted the problematic nature of conventional

(C) Ruth Evans and Felicity Thomas, 12/8/09. Please cite article as: Evans, R. and Thomas, F. (2009) 'Emotional interactions and an ethic of care: caring relations in families affected by HIV and AIDS', Emotions, Space and Society, 2, 111-119. 
notions of 'care', 'dependency' and 'autonomy' that establish a fixed binary opposition between the roles of 'care-giver' and 'care-receiver'. Researchers have recognised that caring relationships are rarely simply a 'one-way' process of 'giving' by one person to another, but rather are characterised by reciprocity and interdependence, in which both the person living with illness or disability and the 'carer' help to care for each other in practical and emotional ways (Evans and Becker, 2009). The theoretical approach to an ethics of care provided by Tronto (1993) and Sevenhuijsen (1998) recognises the interdependence and interconnectedness of human relations, responsibilities and practices of care. From this perspective, caring is valued as a daily practice in everyone's lives and it is acknowledged that there is no absolute or fixed division of roles between 'care-giver' and 'care-receiver' (Sevenhuijsen, 1998; Tronto, 1993). As Williams $(2001,487)$ notes, this ethics of care perspective thus recognises that 'vulnerability is a human condition and that some people are constituted as more or less vulnerable than others, at different times and in different places'.

In this article, we draw on Tronto's (1993) and Sevenhuijsen's (1998) contextual approach to an ethics of care $^{2}$, which emphasises the ways that access to the resources needed to provide and receive care are determined by social relations and social, economic and political power inequalities. Tronto and Fisher define care as:

'a species activity that includes everything that we do to maintain, continue and repair our 'world' so that we can live in it as well as possible. That world includes our bodies, our selves, and our environment, all of which we seek to 
interweave in a complex, life-sustaining web' (Tronto and Fisher, cited in Tronto, 1993, 103).

Care is seen as an ongoing process which is 'both a practice and a disposition', that involves 'taking the concerns and needs of the other as the basis for action' (Tronto, 1993, 105). Four phases of the caring process are identified: 'caring about'; 'taking care of'; 'care-giving'; and 'care-receiving'. Linked to these, four core ethical values emerge: attentiveness - being attentive to the needs of others; responsibility, which is 'embedded in implicit cultural practices'; competence to provide good care, which includes the availability of adequate resources; and responsiveness of the carereceiver to the care, that is, seeking to understand the needs of others by considering 'the other's position as that other expresses it' (Tronto, 1993, 131-136). In this analysis, 'good care' is based on the integration of these four phases of the caring process into an appropriate whole (Tronto, 1993, 136).

Tronto $(1993,109)$ acknowledges that the ideal of an integrated process of care is rarely achieved, due to the likelihood of conflict, often between caregivers' needs to care for themselves and the care they give to others, and the limited availability of adequate material or other resources. Commentators recognise that care work continues to be devalued due to its association with privacy, emotion and the 'othering' of those who are in need (Tronto, 1993; Sevenhuijsen, 1998; 2000). In many societies, care continues to be gendered as women's responsibility primarily because of the emotional labour of care work both at a societal and individual level (Sevenhuijsen, 2000).

(C) Ruth Evans and Felicity Thomas, 12/8/09. Please cite article as: Evans, R. and Thomas, F. (2009) 'Emotional interactions and an ethic of care: caring relations in families affected by HIV and AIDS', Emotions, Space and Society, 2, 111-119. 
Recent research from both the UK and Sub-Saharan Africa suggests that caring relationships in the context of HIV and AIDS-related illness are characterised by a sense of negotiated interdependence and mutual emotional support and guidance (Tisdall et al., 2004; Evans and Becker, 2009; Evans, forthcoming). While the identity of 'carer' may be recognised and embraced, in many families it may be contested and conceptualised as a 'normal' everyday part of family responsibilities, due in part to the episodic nature of HIV-related illness, particularly in the UK context where people have access to high quality medical care and a balanced diet. People with HIV may live 'well' with HIV for many years and hence not require higher levels of care until later stages of the illness trajectory, thereby refuting fixed notions of dependency and caregiving roles.

While previous studies have drawn on Tronto's approach to an ethics of care to develop political geography and social justice analyses of care (Brown, 2003; Barnes, 2006), few studies have used this framework to explore the emotional dynamics of caring relations. Ethics of care perspectives, however, emphasise the 'centrality of social relations and emotions' to understanding the social world, since complex power relations are embedded in emotions and affective relations (Lawson, 2007, 3). Tronto's (1993) four phase model of an ethics of care provides a useful framework for conceptualising disposition and responsibility to care, emotional interactions within caring relationships, as well as the ways caring practices and emotions in families affected by HIV and AIDS are embedded in wider structural inequalities and power relations.

(C) Ruth Evans and Felicity Thomas, 12/8/09. Please cite article as: Evans, R. and Thomas, F. (2009) 'Emotional interactions and an ethic of care: caring relations in families affected by HIV and AIDS', Emotions, Space and Society, 2, 111-119. 


\section{Emotions and geographies of care}

Recent literature on emotional geographies has emphasised the interlinkages between people and the location of emotion in both bodies and places (Anderson and Smith, 2001; Bondi, 2005a; Thien, 2005). Commentators have theorised the ways that people feel and think through their bodies, while at the same time, highlighting the ways in which emotions are intricately bound up with identity and social relations (Mehta and Bondi 1999; Davidson and Milligan, 2004). This is especially evident in geographies of care and geographies of health, in which people living with illness or disability and their carers negotiate multifaceted and often perplexing emotions (Dyck, 1999; Allen, 2001; Parr, 2003; Thomas, 2006). Studies have revealed the importance of the context and meanings invested in a particular location or space in order to understand people's emotional wellbeing (Morris and Thomas, 2005; Milligan, 2005; Bosco, 2007; McLoughlin and Warin, 2008). Research highlights the ways in which decisions over the placement of care are made and the emotions which result for carers and chronically ill or disabled people during the transition between private and public spaces of care (Milligan, 2005; Brown, 2003).

A growing body of work explores the socio-spatiality of emotions in care work in contexts in which people's ability to negotiate transitions of care are severely restricted and informal carers remain largely unheard and invisible (Robson et al., 2006; Thomas, 2006; Evans, forthcoming). While few studies explore the perspectives of both caregivers and care-receivers, Bondi $(2008,250)$ highlights the ways that care 'connects people, whether they desire such connectedness or not', and

(C) Ruth Evans and Felicity Thomas, 12/8/09. Please cite article as: Evans, R. and Thomas, F. (2009) 'Emotional interactions and an ethic of care: caring relations in families affected by HIV and AIDS', Emotions, Space and Society, 2, 111-119. 
these connections are imbued with multiple, often contradictory emotions which are bound up with power relations. Drawing on psychotherapeutic approaches, Bondi suggests that the notion of 'empathic understanding' enables caregivers to 'imaginatively identify with care-recipients without confusing their own feelings with those they imagine to be felt by care-recipients. It is equally what enables carerecipients to imagine what it might be like for care-givers to do what they do' (2008, 260). She explains that this fosters good communication between caregivers and carereceivers which helps to ensure that adequate feedback about whether needs for care have been met, corresponding to Tronto's ethical value of 'responsiveness'.

This paper seeks to contribute to existing research on emotional geographies and geographies of care by examining the ways in which the emotional labour of the caring process may be played out in highly embodied ways through displays (and restriction) of emotion, the performance of daily activities and through socio-bodily practices such as food consumption and denial. In interpreting the emotional dynamics of caring relationships, our emphasis is on the relational nature of everyday performances of care and emotional work, the expression and regulation of emotions by both caregivers and care-receivers and the ways these relations are embedded in dominant gender and generational power imbalances.

\section{Research methods}

This article draws on qualitative research from two studies with families affected by HIV and AIDS. A comparative study explored the experiences of children caring for

(C) Ruth Evans and Felicity Thomas, 12/8/09. Please cite article as: Evans, R. and Thomas, F. (2009) 'Emotional interactions and an ethic of care: caring relations in families affected by HIV and AIDS', Emotions, Space and Society, 2, 111-119. 
parents/relatives with HIV in Tanzania and the $\mathrm{UK}^{3}$ (see Evans and Becker, 2009) while an ethnographic study examined the livelihood and social impacts of HIV and AIDS care in Namibia (see Thomas, 2006).

The comparative research was conducted in rural and urban locations in four regions of Tanzania (Dar es Salaam, Arusha, Manyara, Kilimanjaro) and in cities/towns in five regions of England (London, the South East, Eastern, West and East Midlands). In Tanzania, overall HIV prevalence in 2005 was seven per cent among adults (TACAIDS et al., 2005). The Tanzanian government started to provide free antiretroviral therapy in 2005 and by 2007 an estimated 31-50 per cent of people requiring treatment were able to access free anti-retroviral therapy (WHO, 2008). However, the majority of families affected by HIV in Tanzania are unlikely to receive external support due to stigma and disparities in access to voluntary counselling, treatment and care services, particularly in rural areas (TACAIDS et al., 2005). HIV prevalence in the UK has increased rapidly since the late 1990s and an estimated 63,500 adults were living with HIV in the UK in 2005 (UK Collaborative Group for HIV and STI Surveillance, 2006). The prevalence of HIV in England remains highest in London (ibid), where many participants lived. Since the 1990s, effective antiretroviral combination therapies have led to dramatic improvements in the life expectancy of newly diagnosed people, although HIV remains a highly stigmatised illness, which in turn made recruitment for the study difficult.

NGOs and community groups in each country facilitated access to participants and young people and parents were only selected to participate where HIV or AIDS had

(C) Ruth Evans and Felicity Thomas, 12/8/09. Please cite article as: Evans, R. and Thomas, F. (2009) 'Emotional interactions and an ethic of care: caring relations in families affected by HIV and AIDS', Emotions, Space and Society, 2, 111-119. 
been recognised, either medically or by organisations working with family members. In-depth interviews were undertaken with 33 young people (aged 9-24) caring for a parent/relative with HIV, 33 mothers/female relatives with HIV and 27 service providers supporting the families. A range of participatory methods were also used with young people, including photographic diaries of children's care work and life story books, with drawings, sentence completion exercises and a diary of a typical day with stickers to show a range of emotions. Over two thirds of the young people interviewed were girls and young women (23/33) and boys and young men usually only took on caring responsibilities when no female carer was available or shared these responsibilities with a female carer. Of the 10 boys and young men engaged in care work, 8 lived in Tanzania. Boys' greater involvement in care work in Tanzania compared to the UK is likely to be linked to the greater demand for care within the family in the context of the HIV and AIDS epidemic in Sub-Saharan Africa and the lack of alternative care, as discussed earlier. The majority of young people (13/24 in Tanzania; 10/14 in England) cared for their mother and sometimes younger siblings with HIV in one parent households. Many of the families interviewed in England were African migrant or refugee families granted indefinite leave to remain in the UK or British citizenship (8/14), while three African families were seeking asylum or had insecure immigration status and three families were long-standing British citizens.

The research in Namibia was focused in three rural villages in the Caprivi Region where HIV prevalence levels were reported at $43 \%$ amongst adults (MOHSS, 2004) ${ }^{4}$. At the time the research was undertaken, the cost of an HIV test, the stigma associated with a positive diagnosis and the extremely limited availability of anti-retroviral 'Emotional interactions and an ethic of care: caring relations in families affected by HIV and AIDS', Emotions, Space and Society, 2, 111-119. 
treatment meant that very few people in the research sites here were aware of their HIV status ${ }^{5}$. However, the majority of participants reported situations in which the age and symptoms of the ill person were consistent with AIDS-related illness.

A range of methods were used to obtain insight into the physical and emotional nature of the caring process in Namibia including: three community meetings using participatory methods (health timelines and diagramming showing changing perceptions of illness over time and linking understandings of illness aetiology and impact - see Thomas, 2005); twelve focus groups (three with men and three with women aged $18-59$, three with widows and three with people aged over 60$)^{6}$; in-depth repeat interviews with twelve households who had been, or were currently involved in, long-term caring; and solicited diaries (written and autophotographic) kept by seven people living with chronic illness and their carer. Socio-cultural norms and expectations in the Caprivi Region meant that in almost all of the families in this research, women were the caregivers and usually received only very limited help from men. When help from men was forthcoming, it was with practical duties such as taking the ill person (if a male) to the toilet and transporting the ill person to the clinic. Indeed, men in the Caprivi Region readily admitted that the emotional nature of care work placed it firmly within the realms of women's work.

Space does not permit an in-depth examination of the emotionality of the research process here (for discussion of these issues see Widdowfield, 2000; Meth with Malaza, 2003; Bondi, 2005b). However, we acknowledge that conducting fieldwork on potentially distressing topics such as a highly stigmatised, life-limiting illness and 'Emotional interactions and an ethic of care: caring relations in families affected by HIV and AIDS', Emotions, Space and Society, 2, 111-119. 
caring relationships in contexts of resource scarcity may elicit profound emotional responses from participants and is also likely to have some emotional impact on us as researchers. Despite efforts to minimise potential distress within the interview setting, several carers in Namibia and some girls and a few mothers in Tanzania were tearful when sharing their life stories, expressing their sadness, grief and despair about their situation. Some carers felt overwhelmed by their caring responsibilities, but appeared to value the rare opportunity to talk about their emotions and experiences. As researchers we needed to manage our own emotions during interactions with participants, but found we had few opportunities to talk about emotional aspects of the research with others, due in part to the need for confidentiality in the field. Awareness of the emotional impact of the research on us is likely to have heightened our sensitivities to the emotional experiences felt by those involved in caring relationships.

\section{Emotional connections and mutual emotional support within caring relationships}

The research in Namibia, Tanzania and the UK suggests that caregiving often leads to the development of close emotional bonds between the ill person and the carer. In all the research sites, young people and female relatives caring for family members with HIV saw their care work as part of their love, moral duty and reciprocal responsibilities towards their family. Existing emotional attachments and sociocultural expectations thus motivated carers' disposition to care and correspond to the ethical values of 'attentiveness' and 'responsibility' (Tronto, 1993). In Tanzania, for

(C) Ruth Evans and Felicity Thomas, 12/8/09. Please cite article as: Evans, R. and Thomas, F. (2009) 'Emotional interactions and an ethic of care: caring relations in families affected by HIV and AIDS', Emotions, Space and Society, 2, 111-119. 
example, June ${ }^{7}$ said: "I feel quite normal because this is my mother, I can't abandon her, I thank God for everything and pray that God gives me the strength to persevere until the end. I can't walk away from my responsibility, because she's my mother'. Young people's disposition to care for their parents was influenced by African sociocultural concepts of childhood and the reciprocal responsibilities of children towards their families and communities, in terms of caring and providing for parents and relatives in sickness and old age as part of an "intergenerational contract" (Van Blerk and Ansell, 2007). Similarly, in Namibia, many of the women who were, or had been involved in caring, accepted the extra work load and their responsibility to care for the ill person due to close familial relationships and gendered socio-cultural expectations. In most families, carers looked after their child, husband, sister or grandchild.

Many young people in Tanzania and the UK thought that their parent's illness and their caring responsibilities had strengthened the close, loving relationship they experienced with their parent, as Emily (from East Africa, living in the UK) commented about her relationship with her father:

It makes the relationship close, because like he knows you're there for him, kind of thing, say if he didn't have the illness it would be a different story, yes the relationship would be there but it would be different. [...] Now I know he's around like if I needed to speak to him about something he's there. Or even if I needed something because the fact that mum's not around, he's kind of the only person we've got in our life.

(C) Ruth Evans and Felicity Thomas, 12/8/09. Please cite article as: Evans, R. and Thomas, F. (2009) 'Emotional interactions and an ethic of care: caring relations in families affected by HIV and AIDS', Emotions, Space and Society, 2, 111-119. 
As this example suggests, many caring relationships were characterised by a sense of reciprocity and mutual emotional support, as both children and parents provided and received emotional support, advice and guidance. The emotional support that young people provided included talking and comforting their parent/relative in dealing with the emotional impacts of living with HIV and related mental health problems, giving them hope and reassurance, offering advice, keeping them company and 'being there' for them when they needed support. For example, June (Tanzania) commented on the ways she tried to comfort her mother:

She cries most of the time but I comfort her saying it is not her fault and that I don't like seeing her in that state. I have to do whatever it takes to see to it that she is comfortable because I know if she's upset, she will carry on getting worse. So I have to help take her mind off it.

Children in all three study sites were clearly profoundly important to ill mothers' sense of self and emotional wellbeing, providing a reason to survive and live positively with HIV for as long as possible, confirming the findings of previous research with HIV-positive mothers (Doyal and Anderson, 2005; Ciambrone, 2001; Wilson, 2007). In Namibia, people living with illness reported that children also played a particularly important role in providing a consistent and non-judgemental source of comfort and support to them. However, despite their illness and the physical and emotional care that children provided, parents maintained their parental roles of providing love, emotional support, advice, guidance and discipline to their children. When young people were asked who they could talk to if they had a problem or were 'Emotional interactions and an ethic of care: caring relations in families affected by HIV and AIDS', Emotions, Space and Society, 2, 111-119. 
worried or upset, most young people in Tanzania and over a quarter in the UK said they would talk to their parent with HIV. This suggests that many children turned to their parent for emotional support, advice and guidance despite parents' ill health and suggests fluidity between the roles of 'caregiver' and 'care-receiver'.

In the UK and Tanzania where the cause of the illness was known, closer relationships between young people and their parents were linked to an awareness of parents' mortality. For example, Juliette (Tanzania) commented: “Whatever happens to her she confides in me.[...] I like being with mum, seeing that she is still alive. I feel at peace and am comforted a lot seeing that she is still with us". Many young people and mothers in Tanzania felt that it was important for children to learn as much from their parents about community life and caring for their siblings while they still had the opportunity. Informal teaching about the reciprocal rights and responsibilities of the child to their family and community represents a key element of the socialisation process for children in Africa (Koda, 2000) and parents made efforts to ensure that their children did not to miss out on this part of their upbringing. Malcolm commented on the advice and guidance he received from his mother, who was very ill with $\mathrm{TB}$ at the time of the interview:

I chat to my mum about things in our neighbourhood. She gives me advice on how to get on with people, how to look after my younger brother and sister, how to live peacefully with them and how to stick together as a family.

(C) Ruth Evans and Felicity Thomas, 12/8/09. Please cite article as: Evans, R. and Thomas, F. (2009) 'Emotional interactions and an ethic of care: caring relations in families affected by HIV and AIDS', Emotions, Space and Society, 2, 111-119. 
Similarly, in the UK, some children and parents felt it was important for children to benefit from their parent's advice and guidance while they were still alive, as Rachel, a mother with HIV from Southern Africa commented:

He's a lovely boy and I can talk to him, I can sit down with him and you know teach him a lot, because I told him that there will be times where I can't be here to talk to him, to do things and while I'm still alive it is good for me to talk to him now because if I'm dead there's no one who will be his mother out there.

In all the research sites, carers' own emotional wellbeing was closely linked to the health and wellbeing of the ill person. In Namibia and Tanzania, carers often gauged the health of the ill person through their appetite for food and performance of activities of daily living, such as washing, dressing and engagement in livelihood activities. In Tanzania, young people were aware of the positive health benefits of helping their parent/relative to eat a balanced, nutritional diet and the importance of overcoming feelings of nausea and loss of appetite, especially when they were taking anti-retroviral drugs. In Namibia, where there was considerable uncertainty about the cause of the illness and most ill relatives had not been diagnosed with HIV, carers commented on their sense of relief and optimism for the future when the person they cared for was feeling well, able to eat, or even undertake livelihood activities, which they saw as a sign of recovery, as Margaret recorded in her diary:

(C) Ruth Evans and Felicity Thomas, 12/8/09. Please cite article as: Evans, R. and Thomas, F. (2009) 'Emotional interactions and an ethic of care: caring relations in families affected by HIV and AIDS', Emotions, Space and Society, 2, 111-119. 
If my daughter will continue to be up and walking like this, everyone in the house will start to feel well. When she woke up, she just washed her face and went to collect firewood and wash dishes and prepare food.......Even myself, I feel free in my heart because she has been able to eat. I am very happy because my daughter seems to be much better than before. I did not know she would reach [live] until the harvesting time.

Carers thus sought to understand the needs of the ill person according to embodied performances of their physical and emotional wellbeing, reflecting the ethical value of 'responsiveness' in the caring process (Tronto, 1993).

Furthermore, the research in Namibia revealed that carers sought to share the pain and discomfort that the ill person was feeling through embodied practices, such as reduced food consumption during periods of illness. While it was reportedly common for illness-affected households to face constraints on the time available to cultivate, collect and cook food, participants emphasised that carers' reduced food consumption was also a physical demonstration of their emotional and moral support for the ill person and their own emotional wellbeing during illness episodes. For example, Gertrude commented:

If a son or husband is sick, I cannot eat as that person is feeling pain so I will also feel their pain. I won't have any appetite to eat as I will be worried that my child is about to die - and with those thoughts I will already be full so I cannot eat any more.

(C) Ruth Evans and Felicity Thomas, 12/8/09. Please cite article as: Evans, R. and Thomas, F. (2009) 'Emotional interactions and an ethic of care: caring relations in families affected by HIV and AIDS', Emotions, Space and Society, 2, 111-119. 
Similarly, Susan commented in a community meeting:

The care taker will become thin because of the emotions. Losing their appetite, they won't eat - those who are looking after [others], they will become thin, thin. Unless when that person dies, that's when they get fed.

Marian who was caring for her daughter wrote in her diary, "I don't feel well when my daughter is sick. Until she gets better is when I can even eat normally. I can't laugh with my friends as I normally do".

This restriction on food consumption and embodiment of the ill person's physical and emotional wellbeing formed part of the intimate bond between the carer and the ill person, whilst others in the household faced no such restrictions. It appeared to be a gender-specific performance of the identity of 'carer' and an expression of women's emotional support for sick family members. Samuel suggested that only women adopted this practice: "Men, they eat, they don't care about that, whether you die or what they will just eat whatever is bought. But women they have too [much] mercy.'”

The close emotional connections within caring relationships and carers' strong sense of empathy and responsiveness to the needs of the 'cared for' could however also lead to considerable upset and anxiety about the future, as carers watched their relative suffer from the emotional and physical effects of illness. Marian (Namibia) for example, revealed her fears after her daughter had told her that "it's better she die

(C) Ruth Evans and Felicity Thomas, 12/8/09. Please cite article as: Evans, R. and Thomas, F. (2009) 'Emotional interactions and an ethic of care: caring relations in families affected by HIV and AIDS', Emotions, Space and Society, 2, 111-119. 
than stay sick while she is not getting any better. So now I'm afraid that one day she may commit suicide or try medicine to kill herself." Many young people in Tanzania and the UK were worried about the life-limiting nature of their parent's illness and afraid of what would happen when their parent died. For some young people in Tanzania, this anxiety was revealed through physical symptoms, such as sleepless nights or losing weight because of 'worrying about everything all the time'. For example, Queenie had cared for her mother until she died and continued to care for her four younger siblings as the head of the household. She felt exhausted, both physically and emotionally, by her caring responsibilities:

I am exhausted. I started when I was at a young age, so things have sort of got on top of me. [...] I get very tired. It reaches a stage where I sit down and cry; I feel I've got the most problems in the world. It is heartbreaking at times when one of the younger ones comes along wanting an exercise book and I don't have the money to buy her one. Or they are sent back [home from school] because I haven't paid the school meals money. So then I feel I am really letting them down because I can't meet their needs. I sometimes have sleepless nights thinking about how I can make things easier for my younger siblings.

This reveals the difficult emotional labour that carers may be engaged in over an extended period of time and the effects this can have on carers' own emotional and physical wellbeing.

(C) Ruth Evans and Felicity Thomas, 12/8/09. Please cite article as: Evans, R. and Thomas, F. (2009) 'Emotional interactions and an ethic of care: caring relations in families affected by HIV and AIDS', Emotions, Space and Society, 2, 111-119. 


\section{Regulating emotions within caring relationships}

As we have discussed, the close emotional connections between caregivers and carereceivers meant that the disposition to care was characterised by a strong sense of moral responsibility and 'empathic understanding' with their ill relative (Bondi, 2008, 260), leading to a high level of responsiveness in caring practices. However, evidence from the three countries suggests that concern about the emotional wellbeing of the other person within the caring relationship could also lead to both caregivers and carereceivers regulating their emotions and managing their 'presentation of self' in an attempt to reduce the emotional burden of HIV and AIDS care (Goffman, 1959). Goffman's (1959) metaphor of 'front-stage' and 'back-stage' performances to describe the ways that people seek to manage their presentation of self in everyday life is useful here in understanding caregivers' and care-receivers' narratives of their negotiation of changing health identities and embodiment of 'the ritual drama of sickness', which can be seen as both an individual and relational process (James and Hockey, 2007).

While carers feared for the future health and wellbeing of their relatives, people with HIV were also concerned about the effects of their illness on the emotional wellbeing of the carer. In many instances, they sought to minimise their carer's worry and anxiety by hiding their pain and other symptoms of their illness. For example, Joyce (from East Africa living in the UK) said about her daughter:

(C) Ruth Evans and Felicity Thomas, 12/8/09. Please cite article as: Evans, R. and Thomas, F. (2009) 'Emotional interactions and an ethic of care: caring relations in families affected by HIV and AIDS', Emotions, Space and Society, 2, 111-119. 
When I'm well she is happy. But when I tell her I'm in pain or I'm ill she gets sad because she thinks I'm going to die. She gets really sad because she thinks it's all going to come to an end and that I'm going to die so really it's better if I don't tell her when I'm ill. But because I have been with her for such a long time she knows when I'm ill.

Joyce's comments suggest that although people with HIV may seek to manage their performance of their health identity, carers may be able to see beyond these 'frontstage' performances of sickness, due to close emotional connections within caring relationships and carers' responsiveness in seeking to understand the needs of the 'cared for'.

Service providers in the UK thought that parents' practices of hiding their illness so as not to worry their children led to a lack of communication between children and parents which in turn heightened children's fears: "The parents are afraid to tell them any more because they don't want to burden them, but yet the child is really worrying more than they need to because of lack of information". This suggests that parents' attempts to reduce the emotional impacts of living with HIV on their children and conceal their health identities may exacerbate young people's fears, anxieties and sense of uncertainty about the future. Indeed, some young people in Tanzania who had suspected that their parent was living with HIV for some time expressed frustration that their parents had not talked more openly about the nature of their illness earlier. 
While people living with HIV tried to minimise carers' anxieties about their illness through managing their performance of ill health, the research suggests that carers also tried to manage their emotions and hide any emotional upset in order to avoid causing stress or exacerbating their relative's illness. For example, in Namibia, Marian wrote in her diary:

You cannot feel tired when you are caring for your own daughter. If you loved her before she got ill you have to care. Because if you don't care for that patient they will feel that you didn't like them in your life....Mostly I feel bad, but I don't show this to her because when I do so then she starts to feel very bad and her sickness gets worse.

Similarly, young people in Tanzania and the UK were keen to avoid conflict with their parents and siblings, as they knew that this could cause them additional stress and make their illness worse. Sophia (from the Horn of Africa and living in the UK) understood that her mother and sister could get angry and frustrated due to the emotional pressures of living with HIV. She felt that she needed to control her emotions and avoid conflict with them in order to reduce their stress:

Sometimes she gets angry, shouting, I do something wrong yeah and in that situation I have to be calm because I know it's because of that. And with my sister as well the arguments sometimes, and sometimes I do understand that they are ill so then keeping on arguing and things, they get stressed or get angry, so it's better to be quiet.

(C) Ruth Evans and Felicity Thomas, 12/8/09. Please cite article as: Evans, R. and Thomas, F. (2009) 'Emotional interactions and an ethic of care: caring relations in families affected by HIV and AIDS', Emotions, Space and Society, 2, 111-119. 
Some young people articulated a sense of pride in their caring responsibilities, which appeared to help them to deal with their fears about their parent's illness. Alice (from East Africa, living in the UK) sometimes found it difficult caring for her mother, but she thought that she had become stronger emotionally as a result: "Helping my mum is sometimes tough, especially when she is really ill. I get scared and I just try and keep myself strong for her. But helping her has also given me strength to come to terms with her illness, yes". Some young people in Tanzania who had lost their fathers to AIDS-related illness also felt a sense of pride in caring for their mother, which seemed to help them to deal with their grief and fears about their surviving parent's illness.

While caring could be seen as a positive expression of resilience (Evans, 2005), some young people felt that they needed to control their emotions in order to 'cope' and hide their fears and concerns about their parent's illness from both their parent and their peers. Kisha (from East Africa, living in the UK) felt that she had become more confident, outgoing and emotionally mature as a result of caring for her mother, but also felt that this made it more difficult for her to show her emotions in public:

I guess it started the day my mum told me about her illness. In a way, it made me stronger. I remember, I used to show my feelings a lot when I was slightly upset or when things didn't go my way. Now it's different, I never cry in front of someone. I hide my feelings and stay strong, especially at school. 
Furthermore, some mothers with HIV in the UK were worried that their children were more reluctant to turn to them for emotional support due to a fear of causing them stress or emotional upset and making their illness worse. One British mother commented: “You worry that you know they're withholding things because they're scared that it might make you ill or upset you". As a result, she tried to reduce the emotional effects her illness might have on her children by hiding minor illnesses: "I've sort of become very conscious now of trying to not say when I'm not feeling well [...] I don't want to give them undue worries or concerns because I don't, I don't think it's fair on them".

In all the research sites, carers' opportunities to talk about their emotions with relatives, friends or neighbours outside the household were inhibited by the stigma surrounding HIV and fear of wider disclosure within the community. Furthermore, cultural taboos about the public expression of emotions meant that carers' ability to share their emotions with others was very limited in Namibia and Tanzania.

\section{Emotional strains within caring relationships}

Although the love and close emotional connections that developed within caring relations were crucial to the wellbeing of the carer and the ill person, there was also evidence in all three countries that the intimate and often long-term nature of caring could result in tensions and strains within caring relationships. Our findings reveal the difficulty of achieving an integrated process of 'good care' (Tronto, 1993) when 
competence to provide care is restricted by resource constraints and conflicts between the carer's and the care-receiver's needs.

Differences in access to external support and the social location of carers influenced the ways in which these conflicting emotions were manifested ${ }^{8}$. In Namibia, confusion over the cause and likely outcome of the illness was compounded by a lack of treatment availability and the struggle faced by carers in maintaining some level of food and livelihood security, which led to tensions and ill-feelings in several households. While carers felt an obligation to undertake caring duties in the first few months of an illness, they could become tired and less willing if the care-receiver's health did not improve over time. In some families, carers had been looking after their ill relative for over a year under circumstances in which they had access to only very basic medications (such as Paracetemol) and limited social support. Carers' feelings of isolation and stress often led to tensions that disrupted the process of providing 'good care'.

In Namibia, the failure of the chronically ill person to recover caused frustration and irritability for the carer, particularly when they had spent scarce resources upon costly foods and medications. While emotional attachment and social and cultural expectations meant that carers did not desert their duties to the care-receiver, there were instances in which carers temporarily abandoned them when their exasperation and the need to sustain their livelihoods and food security became particularly intense. In one household, the pressures of providing care over a period of three years had led 
to feelings of anger, stress and frustration between the carer and the ill relative as the carer struggled to sustain the household:

The carer is very angry with the patient today and has gone to work in the fields. The carer is angry because Patricia "talks too much" saying that her diarrhoea won't stop because the food she is being given is dirty and unhealthy. No relatives have visited because they are too hungry and don't have any time to spend with Patricia. Patricia reported that she felt a bit better but was angry because if her family really loved her they could have prepared her healthy food. (Julia's diary, recorded by Home Based Care worker)

This reveals the complexity and intensity of caring relationships, characterised at times by contradictory emotions that may be difficult to manage.

In Tanzania and the UK, knowledge of the cause of the illness, more widespread access to anti-retroviral treatment and some level of assistance via support groups meant that families' sense of isolation was usually less extreme ${ }^{9}$. However, some young people and mothers commented on unease and tensions caused by changed roles and responsibilities in the family, particularly in the case of boys who performed caring tasks that subverted conventional gender norms. For example, Malcolm (Tanzania) said that his friends were "surprised when they see me doing the things I do. They say they can't understand why I do what I do. But I have to do these things to help my family”.

(C) Ruth Evans and Felicity Thomas, 12/8/09. Please cite article as: Evans, R. and Thomas, F. (2009) 'Emotional interactions and an ethic of care: caring relations in families affected by HIV and AIDS', Emotions, Space and Society, 2, 111-119. 
Participants in Tanzania and the UK showed a preference for gender matching between the care receiver and caregiver, particularly regarding children's involvement in providing intimate personal care, confirming the findings of previous research (Robson, 2004; Robson et al., 2006; Becker, 2007). In families where the gender of the young person providing care did not match that of their parent/relative, the young person was usually involved in every aspect of their parent/relative's care except personal care; an older relative, friend or neighbour of the same gender as the care receiver was often called on to provide assistance with the toilet or bathing, in order to avoid transgressing the boundaries of bodily intimacy, gender and generational norms (see also Evans, forthcoming). These norms are related to strong cultural taboos about sexuality between genders and generations in many African cultures (Liddell et al., 2005).

However, despite these taboos, there was also evidence that young people were willing to provide intimate personal care for a parent/relative of another gender when faced with a lack of alternatives, as Good Luck (Tanzania) commented:

"I used to bathe her, she didn't mind that I was a boy.[...] According to our culture it is not good [for a boy to bathe his mother], but I had to do it. I used to do everything for her, I couldn't leave her like that when everything was soiled". 
This suggests that young people recognised the importance of the ethical values of attentiveness, responsibility and responsiveness to the needs of their parent, despite dominant socio-cultural norms about the inappropriateness of intimate caring practices across genders and generations.

Furthermore, young people's experiences in Tanzania suggest that carers providing high levels of care may have to negotiate conflicting demands and manage their emotions in order to provide 'good care' that is responsive to the needs of different family members. For example, Maureen (Tanzania) used to care for her step-father who had since died of AIDS-related illness, and continued to care for her mother at the time of the interview. She had found it particularly difficult to care for her stepfather as he directed anger and criticism towards her:

The time when mum was admitted to hospital, I would go visit her and when I got back he would be angry with me and deny me food saying I just go to care for mum, leaving him to die of hunger at home. Sometimes when I was bathing mum, he would criticise me saying I just bathe mum and neglect him. I didn't mind, I would go and help him. I just accepted that his illness was bothering him.

This reveals the complex ways that gendered and generational power relations are embedded in caring practices and emotions.

\section{The 'burden' of care and dependence}

(C) Ruth Evans and Felicity Thomas, 12/8/09. Please cite article as: Evans, R. and Thomas, F. (2009) 'Emotional interactions and an ethic of care: caring relations in families affected by HIV and AIDS', Emotions, Space and Society, 2, 111-119. 
While the ethics of care approach provided by Tronto (1993) recognises that 'vulnerability is a human condition' (Williams, 2001: 487) and emphasises the interdependence that characterises social relations, without adequate resources and a re-valuing of the caring process, care continues to be commonly perceived as a lowstatus activity and a burden on others, characterised by relations of dependence. In the present research, people living with HIV or AIDS-related illness in all three countries perceived their need for care as being a burden on family members. They were acutely aware of the emotional and material impacts of their illness on the carer and expressed their gratitude for the carer's support and continued contact, particularly when they felt that they had been abandoned and stigmatised by others.

In the UK and Tanzania, guilt and regret were commonly expressed by mothers who relied upon their children to look after them, as one British mother commented:

I think it's the guilt and feeling that I'm taking some of his freedom away. And some of his childhood because he has had to grow up quicker and be, be more responsible you know sooner [...] I feel that part of me has sort of stopped his childhood in a way.

Many mothers felt sad and upset that they had no alternative but to rely on their children to care for them. This is linked to normative notions of childhood and parenting, especially motherhood, as young people's caring roles subvert norms of parent-child relations and cultural expectations of childhood and youth ${ }^{10}$.

(C) Ruth Evans and Felicity Thomas, 12/8/09. Please cite article as: Evans, R. and Thomas, F. (2009) 'Emotional interactions and an ethic of care: caring relations in families affected by HIV and AIDS', Emotions, Space and Society, 2, 111-119. 
Ill relatives' discomfort with having to rely on carers to meet their needs was related to culturally defined notions of appropriate care and dependence on family members as well as the wider context of sometimes severe economic pressures on households over a number of years. This could lead to a sense of indebtedness towards family carers. In Namibia, several people expressed their desires to repay their carer if they recovered, and three claimed that they sometimes felt that it would be better if they committed suicide to ease the carer's burden and shame. Ill relatives were extremely worried about their growing reliance on family members and were intensely aware of, and worried about, the time and resource costs that their illness was having on the household. In her diary, Clare explained how her mother was unable to conduct her livelihood activities because of her need for care, and that even when her mother was able to go to her farm, she was very anxious about Clare's illness:

I was very sick today. Mother even went to her fields and came back again.

Her work is not done properly because of caring for me sometimes. Cattle got into her field while she was with me and destroyed her crops. When I get better is when she goes to look after her crops. But that's another problemwhile she is away she just worries that her child has got ill again whiles she has left her behind.

This illustrates the way that 'empathic understanding' (Bondi, 2008, 260) enables care-receivers to imagine the conflicting emotional and material pressures that carers may experience.

(C) Ruth Evans and Felicity Thomas, 12/8/09. Please cite article as: Evans, R. and Thomas, F. (2009) 'Emotional interactions and an ethic of care: caring relations in families affected by HIV and AIDS', Emotions, Space and Society, 2, 111-119. 


\section{Conclusion}

The research with caregivers and care-receivers in families affected by HIV and AIDS in Namibia, Tanzania and the UK has revealed the complex emotional dynamics of the caring process and the ways that gender and generational power inequalities are embedded in caring relations and emotions. Affective familial relationships, sociocultural expectations and gender norms influence carers' disposition and responsibility to care for their relative and everyday practices of care often lead to the development of closer emotional connections between the 'caregiver' and 'carereceiver' and a strong sense of empathy and identification with the 'other' in the caring relationship. Carers and ill relatives negotiate the emotional impacts of a highly stigmatised, life-limiting illness through their performance of activities of daily living and mutual emotional support and through the expression, regulation, and contestation of emotions and health identities. While some family members with HIV, particularly mothers in the UK being cared for by their children, tried to hide symptoms of their illness to protect carers and alleviate their care work, many carers in turn attempted to regulate their emotions and 'stay strong' for their relative. Carers' own emotional wellbeing was however closely connected to the physical and emotional wellbeing of their ill relative and the negative impacts of living with lifelimiting illness were often revealed through carers' anxiety, uncertainty and fears about the future. Furthermore, in Namibia, carers' emotional support for their relative and their identity as carers was performed through gender-specific bodily practices, such as reduced food consumption.

(C) Ruth Evans and Felicity Thomas, 12/8/09. Please cite article as: Evans, R. and Thomas, F. (2009) 'Emotional interactions and an ethic of care: caring relations in families affected by HIV and AIDS', Emotions, Space and Society, 2, 111-119. 
Our research demonstrates the relevance of an ethics of care perspective to theorising the emotional dynamics of the caring process. Caring practices, emotions and social interactions between caregivers and care-receivers were characterised by the four ethical values of attentiveness, responsibility, competence and responsiveness (Tronto, 1993). However, the research also reveals that an integrated process of care was often disrupted when conflicts arose between the household's or carer's needs and those of the 'cared for'. Carers' competence to provide good care, particularly in the Sub-Saharan African context, was undermined by poverty, insufficient material resources and the need to sustain livelihood activities. In the UK, African migrant families faced additional emotional pressures linked to insecure immigration status and sometimes traumatic migration histories and separation from close family members (Evans, forthcoming). These pressures, contradictory emotions and tensions within caring relationships in Namibia, Tanzania and the UK were exacerbated by stigmatisation and ostracism from extended family members, friends and others in the community, which further undermined the ability of caregivers and care-receivers to seek external support or share their emotions with others outside the household.

An ethics of care approach has highlighted the fluid and interdependent nature of caring roles in households affected by HIV and AIDS, as both the 'carer' and the 'cared for' are engaged in a dynamic two-way process of giving and receiving care and emotional support. However, the research suggests that, when unsupported, providing high levels of care over extended periods of time could have negative emotional and material consequences for carers and could lead to physical and 'Emotional interactions and an ethic of care: caring relations in families affected by HIV and AIDS', Emotions, Space and Society, 2, 111-119. 
emotional exhaustion and potential 'burnout'. Carers in Sub-Saharan Africa may also be involved in providing intensive nursing care for a close family member during the final stages of their life, which could cause considerable distress and anticipatory grief. The emotional dynamics of care, therefore, need to be understood within the wider context of unequal gender and generational power relations and institutional and cultural expectations that continue to construct care work primarily as the responsibility of unpaid, usually female, family members within the private sphere of the household. The lack of access to adequate resources, combined with the stigma associated with HIV and AIDS, can result in considerable isolation and intense emotional pressures for carers and people living with HIV. Proponents of an ethics of care, however, advocate that ethical values of care should represent the starting point for the development of social policies and interventions in all sectors and social institutions (Sevenhuijsen, 2000; Barnes, 2006). Such an approach to social justice that values care as an everyday practice that is embedded in social relations is likely to offer greater recognition of the differential gendered and age-related caring roles and the difficult emotional work that caregivers and care-receivers are engaged in. This approach would also provide greater opportunities for the development of an integrated process of material and emotional care and support for both carers and people living with HIV and AIDS.

\section{Notes}

1. Due to differences in research methods and samples used in the two studies, we do not seek to provide a systematic, comparative analysis of the findings from the

(C) Ruth Evans and Felicity Thomas, 12/8/09. Please cite article as: Evans, R. and Thomas, F. (2009) 'Emotional interactions and an ethic of care: caring relations in families affected by HIV and AIDS', Emotions, Space and Society, 2, 111-119. 
three countries. Instead, we have reviewed data from each study to draw out common themes.

2. While in this paper, we draw on Tronto's (1993) and Sevenhuijsen's (1998) approach to an ethics of care, we acknowledge Gilligan's (1977; 1982) significant contribution to theoretical debates on ethics of care.

3. The research was funded by the Economic and Social Research Council, UK 2006-2007, grant number RES-000-22-1732-A.

4. The high HIV prevalence in the Caprivi Region is related to: the proximity of the region to affected neighbouring countries; the region's location on a major truck and trade route; gender disparities which undermine women's power within relationships; high levels of HIV stigma and denial; and the generally poor health profile of the region (see Thomas, 2005).

5. In addition to the cost of an HIV test (approximately N\$10), people living at a distance from the region's only hospital had to pay for transport costs to and from the town, to take the test and to collect the results. Anti-retroviral drugs were extremely difficult to access without recourse to expensive private doctors, an option beyond the means of most households.

6. Focus groups with men and women explored the gendered nature of livelihoods, relationships and care work. Discussions with widows elicited insight into impacts of spousal death on the social, cultural and economic wellbeing of women, while focus groups with elderly people (both men and women) examined changing perceptions of illness and ideas regarding culturally acceptable behaviour.

7. The names of all participants have been changed to protect their anonymity. 
8. The different experiences discussed here may also have been influenced by the different methodologies employed by the two studies.

9. Largely as a result of recruitment methods via NGOs, most participants in Tanzania and the UK received some support from local organisations. The majority of mothers with HIV in both countries regularly attended peer support groups; most young people in the UK regularly attended social activities for young people affected by HIV and/or received one-to-one emotional support, while governmental welfare support and health care was available for parents in the UK (although entitlements depended on immigration status). Most families in Tanzania received minimal material support from home-based care programmes, but few young people had formal opportunities for emotional or peer support. In Namibia, very limited support e.g. basic medications, food and spiritual support, was provided by home-based care programmes. As in Tanzania, very few formal opportunities existed for people to access emotional support.

10. Children's caring roles challenge Western constructions of childhood and parenting, in which children are seen as dependent on their parents during a 'carefree' phase of innocence in which they are protected from 'adult' responsibilities and concerns. These notions have become increasingly globalised through international development and human rights discourses (Boyden, 1997), although they intersect with locally defined concepts and norms of childhood and parenting cultures. See Evans and Becker (2009) and Evans (forthcoming) for further discussion of these issues.

\section{References}

(C) Ruth Evans and Felicity Thomas, 12/8/09. Please cite article as: Evans, R. and Thomas, F. (2009) 'Emotional interactions and an ethic of care: caring relations in families affected by HIV and AIDS', Emotions, Space and Society, 2, 111-119. 
Allen, Chris. 2001. Back to the old house? 'Sick role' and biographical narratives of the housing needs of short stay hospital patients. Health and Place 7: 81-92

Anderson, Kay and Susan Smith. 2001. Editorial: emotional geographies.

Transactions of the Institute of British Geographers, 26, 7-10.

Barnes, Marian. 2006. Caring and Social Justice. Basingstoke: Palgrave MacMillan.

Becker, Saul. 2007. Global perspectives on children's unpaid caregiving in the family: research and policy on 'young carers' in the UK, Australia, the USA and Sub-Saharan Africa. Global Social Policy 7(1): 23-50.

Bondi, Liz. 2008. On the relational dynamics of caring: a psychotherapeutic approach to emotional and power dimensions of women's care work. Gender, Place and Culture 15(3): 249-265.

Bondi, Liz. 2005a. Making connections and thinking through emotions: between Geography and Psychotherapy". Transactions of the Institute of British Geographers 30: 433-448.

Bondi, Liz. 2005b. The place of emotions in research: from partitioning emotion and reason to the emotional dynamics of research relationships. In Joyce Davidson, Liz Bondi and Mick Smith, Emotional Geographies, Aldershot: Ashgate, 231-246.

(C) Ruth Evans and Felicity Thomas, 12/8/09. Please cite article as: Evans, R. and Thomas, F. (2009) 'Emotional interactions and an ethic of care: caring relations in families affected by HIV and AIDS', Emotions, Space and Society, 2, 111-119. 
Bosco, Fernando. J. 2007. Emotions that build networks: geographies of human rights movements in Argentina and beyond. Tijdschrift voor Economische en Sociale Geografie 98(5): 545-563.

Boyden, Jo. 1997 Childhood and the Policy Makers: A Comparative Perspective on the Globalization of Childhood. In A. James and A. Prout, Constructing and Reconstructing Childhood, London: Falmer Press, 190-229.

Brown, Michael. 2003. Hospice and the spatial paradoxes of terminal care. Environment and Planning A, 35: 833-851.

Ciambrone Desirée. 2001. Illness and other assaults on self: the relative impact of HIV/AIDS on women's lives. Sociology of Health and Illness. 23(4): 517-540.

Davidson, Joyce and Christine Milligan. 2004. Embodying emotion sensing space: introducing emotional geographies. Social and Cultural Geography, 5 (4): 523-532.

Doyal, Lesley and Jane Anderson. 2005. "My fear is to fall in love again...." How HIV-positive African women survive in London. Social Science and Medicine, 60: 1729-1738.

Evans, Ruth. Forthcoming. Young caregiving and HIV in the UK: caring relationships and mobilities in African migrant families. Population, Space and Place.

(C) Ruth Evans and Felicity Thomas, 12/8/09. Please cite article as: Evans, R. and Thomas, F. (2009) 'Emotional interactions and an ethic of care: caring relations in families affected by HIV and AIDS', Emotions, Space and Society, 2, 111-119. 
Evans, Ruth. 2005. Social networks, migration and care in Tanzania: caregivers' and children's resilience to coping with HIV/AIDS. Children and Poverty 11(2): 111-129.

Evans, Ruth and Saul Becker. 2009. Children Caring for Parents with HIV and AIDS:

Global Issues and Policy Responses, Bristol: The Policy Press.

Finch Janet and Dulcie Groves. 1983. A Labour of Love: Women, Work and Caring. London: Routledge and Kegan Paul Plc.

Gilligan Carol. 1977. In a different voice: Women's conceptions of self and of morality. Harvard Educational Review, 47, 4, 481-517.

Gilligan Carol. 1982. In a Different Voice: Psychological Theory and Women's Development. Cambridge, Mass., Harvard University Press.

Goffman Erving. 1959 The Presentation of Self in Everyday Life, London, Penguin Books.

Graham, Hilary. 1983. Caring: a labour of love. In Janet Finch and Dulcie Groves, Eds. A Labour of Love: Women, Work and Caring. London: Routledge and Kegan Paul Plc: 13-30.

(C) Ruth Evans and Felicity Thomas, 12/8/09. Please cite article as: Evans, R. and Thomas, F. (2009) 'Emotional interactions and an ethic of care: caring relations in families affected by HIV and AIDS', Emotions, Space and Society, 2, 111-119. 
James, Allison and Jenny Hockey. 2007. Embodying Health Identities. Palgrave MacMillan, Houndmills, Basingstoke.

Koda, Bertha. 2000. Democratisation of social relations at the household level: The participation of children and youth in Tanzania. In Colin Creighton and Cuthbert K. Omari, Eds. Gender, Family and Work in Tanzania. Aldershot: Ashgate; 237-265.

Lawson, Victoria. 2007. Geographies of care and responsibility. Annals of the Association of American Geographers, 97(1): 1-11.

Liddell, Christine, Louise Barrett and Moya Bydawell. 2005. Indigenous representations of illness and AIDS in Sub-Saharan Africa. Social Science and Medicine, 60: 691-700.

McLoughlin, Pauline and Megan Warin. 2008. Corrosive places, inhuman spaces: mental health in Australian immigration detention. Health and Place 14: 254-264.

Mehta, Anna and Liz Bondi. 1999. Embodied discourse: on gender and fear of violence. Gender, Place and Culture 6(1): 67-84

Meth, Paula with Malaza, Knethiwe. 2003. Violent research: the ethics and emotions of doing research with women in South Africa. Ethics, Place and Environment 6(2): $143-159$

(C) Ruth Evans and Felicity Thomas, 12/8/09. Please cite article as: Evans, R. and Thomas, F. (2009) 'Emotional interactions and an ethic of care: caring relations in families affected by HIV and AIDS', Emotions, Space and Society, 2, 111-119. 
Milligan, Christine. 2003. Location or dis-location? Towards a conceptualization of people and place in the care-giving experience. Social and Cultural Geography 4(4): 455- 470.

Milligan, Christine. 2005. From home to 'home': situating emotions within the caregiving experience. Environment and Planning A, 37: 2105-2120.

MOHSS 2004. 2004 HIV/AIDS Sentinel Sero-Survey Results. Windhoek: MOHSS.

Morris, Sara. M. and Carol Thomas. 2005. Placing the dying body: emotional, situational and embodied factors in preferences for place of final care and death in cancer. Ed. Joyce Davidson, Liz Bondi, and Mick Smith, Emotional Geographies, Aldershot: Ashgate, pp. 19-32.

Morris, Jenny. 1991. Pride Against Prejudice: Transforming attitudes to disability, Philadelphia: New Society Publishers.

Ogden, Jessica, Simel Esim and Caren Grown. 2006. Expanding the care continuum for HIV/AIDS: bringing carers into focus. Health Policy and Planning 21(5): $333-$ 342.

Oliver, Michael. 1990. The Politics of Disablement. Basingstoke: Macmillan and St. Martin's Press.

(C) Ruth Evans and Felicity Thomas, 12/8/09. Please cite article as: Evans, R. and Thomas, F. (2009) 'Emotional interactions and an ethic of care: caring relations in families affected by HIV and AIDS', Emotions, Space and Society, 2, 111-119. 
Robson, Elsbeth. 2004. Hidden child workers: Young Carers in Zimbabwe. Antipode 36(2): 227-248.

Robson, Elsbeth, Nicola Ansell, Ulli Huber, William Gould and Lorraine van Blerk. 2006. Young caregivers in the context of the HIV/AIDS pandemic in sub-Saharan Africa. Population, Space and Place, 12: 93-111.

Sevenhuisjsen, Selma. 2000. Caring in the third way: the relation between obligation, responsibility and care in Third Way discourse. Critical Social Policy 20 (1): 5-37.

Sevenhuijsen, Selma. 1998. Citizenship and the Ethics of Care. Feminist Considerations on Justice, Morality and Politics. London and New York: Routledge.

Shakespeare, Tom. 1993. Disabled people's self-organisation: a new social movement? Disability, Handicap and Society 8(3): 249-264.

Sparr, Pamela. 1994. Mortgaging Women's Lives: Feminist Critiques of Structural Adjustment. London: Zed Books.

Tanzania Commission for AIDS (TACAIDS), National Bureau of Statistics (NBS) and ORC Macro. 2005. Tanzania HIV/AIDS Indicator Survey 2003-04. Calverton, Maryland, USA: TACAIDS, NBS and ORC Macro.

(C) Ruth Evans and Felicity Thomas, 12/8/09. Please cite article as: Evans, R. and Thomas, F. (2009) 'Emotional interactions and an ethic of care: caring relations in families affected by HIV and AIDS', Emotions, Space and Society, 2, 111-119. 
Thien, Deborah. 2005. After or beyond feeling? A consideration of affect and emotion in Geography. Area 37: 450-456.

Thomas, Felicity. 2005. 'Seeing for yourself' - exploring the impacts of HIV/AIDS and chronic illness on livelihoods, vulnerability and support networks in the Caprivi Region, Namibia. Unpublished PhD thesis, University of Sheffield.

Thomas, Felicity. 2006. Stigma, fatigue and social breakdown: exploring the impacts of HIV/AIDS on patient and carer well-being in the Caprivi Region, Namibia. Social Science and Medicine 63: 3174-3187.

Tisdall, Kay, Helen Kay, Vivienne Cree and Jennifer Wallace. 2004. Children in Need? Listening to Children whose Parent or Carer is HIV Positive. British Journal of Social Work 34: 1097-113.

Tronto, Joan. 1993. Moral Boundaries. A Political Argument for an Ethic of Care. New York and London: Routledge.

UK Collaborative Group for HIV and STI Surveillance. 2006. A Complex Picture. HIV and other Sexually Transmitted Infections in the United Kingdom: 2006, Health Protection Agency, Centre for Infections: London. 
Van Blerk, Lorraine and Nicola Ansell. 2007. Alternative strategies for care giving in the context of AIDS in Southern Africa: complex strategies for care. Journal of International Development 19, 865-884.

Widdowfield, Rebekah. 2000. The place of emotions in academic research. Area 32: 199-208.

Williams, Fiona. 2001. In and beyond New Labour: towards a political ethics of care. Critical Social Policy 21(4): 467-493.

Wilson, Sarah. 2007. "When you have children, you're obliged to live": motherhood, chronic illness and biographical disruption. Sociology of Health and Illness 29(4): 610-629.

World Health Organisation (WHO). 2008. Towards Universal Access: Scaling Up Priority HIV/AIDS Interventions in the Health Sector. Progress Report 2008, Geneva: WHO. 